\title{
Insights Into the Degradation of Carbamazepine by Persulfate Activated by Chalcopyrite冈degradation Mechanism and Synergy With Zero-valent Iron
}

\section{GaoYang Xi}

Zhengzhou University

\section{Shunxun Chen}

Zhengzhou University

Xuhang Zhang

Zhengzhou University

Yu Xing

Zhengzhou University

Zhengguang He ( $\nabla$ Hezhengguang008@163.com )

Zhengzhou University

\section{Research Article}

Keywords: Carbamazepine, Chalcopyrite, Persulfate, Degradation, Fe0

Posted Date: January 24th, 2022

DOI: https://doi.org/10.21203/rs.3.rs-1157599/v1

License: (c) (1) This work is licensed under a Creative Commons Attribution 4.0 International License. Read Full License 


\section{Abstract}

In this study, natural chalcopyrite (NCP) was used to activate peroxymonosulfate (PMS) to oxidatively degrade carbamazepine (CBZ). The physical and chemical properties before and after the NCP reaction were characterized by Scanning electron microscope and energy spectrometer $₫ S E M-E D S \bigotimes, X$-ray

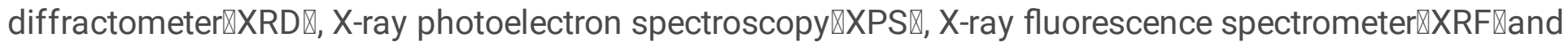
Vibration sample magnetometer $\mathrm{VS} \mathrm{SM} \otimes$. The effects of the amount of NCP and PMS, the initial pH value, and the reaction temperature on the catalytic performance of NCP were systematically studied. The research results show that the degradation efficiency of NCP/PMS system for CBZ can reach $82.34 \%$ under the optimal reaction conditions, and the degradation process follows a pseudo-second-order kinetic model. The results of radical quenching experiment and EPR analysis show that the active species in the system are $\mathrm{OH} \bullet, \mathrm{SO}_{4} \bullet$ and ${ }^{1} \mathrm{O}^{2}$, of which $\mathrm{SO}_{4} \bullet$ is the main active species. In addition, this study shown that only with the assistance of $0.15 \mathrm{~g} / \mathrm{L} \mathrm{Fe}^{0}$, the efficiency of the NCP/PMS system to degrade CBZ can be as high as $90.73 \%$. This study determined the optimal reaction conditions for natural chalcopyrite to activate PMS to degrade CBZ and clarified the activation mechanism, which broadened the application of natural ores in the field of water treatment.

\section{Introduction}

Carbamazepine (CBZ) is a common pharmaceutical compound used to relieve neuralgia, treat epilepsy and various mental illnesses(Y.F. Rao et al.2014). Approximately 1014 tons of CBZ are used every year in the world, and its annual usage ranks among the top three among all anti-epileptic drugs in China (Yongjun Zhang et al.2008).Unfortunately, CBZ has stable chemical properties and poor biodegradability, and can only be partially removed after the sewage treatment plant. The treated wastewater will be used for irrigation, causing soil and groundwater to be contaminated to a certain extent(C.G.Daughton et al.1999). Trace amounts of carbamazepine have been detected in a variety of water bodies and soils, so the development of a fast and effective method to degrade CBZ is imminent.

The current methods of removing carbamazepine are roughly divided into biological methods(Jean-Rene Thelusmond et al.2018), adsorption(Nakorn Suriyanon et al.2013), electrolysis(Liu, K Thelusmond et al.2018), photocatalysis and advanced oxidation process (AOPs)(Jian Xu et al.2013;M. Checa et al.2020). Based on the poor biodegradability of carbamazepine and the biological method is difficult to degrade, AOP is the most effective method to degrade carbamazepine wastewater(Jianlong Wang et al.2016). The advanced oxidation process uses strong oxidants such as $\mathrm{H}_{2} \mathrm{O}_{2}$ (Junxue Wu et al.2020), $\mathrm{O}_{3}$ (Guangfei Yu et al.2020), $\mathrm{KMnO}_{4}\left(\mathrm{Yi}\right.$ Shi et al.2019) and $\mathrm{K}_{2} \mathrm{~S}_{2} \mathrm{O}_{8}(\mathrm{PS})$ (Majid Kermani et al.2018) to degrade organic pollutants. However,these common oxidants have some shortcomings and limitations. The $\mathrm{H}_{2} \mathrm{O}_{2}$-based Fenton oxidation technology has a narrow application range for $\mathrm{pH}$, while the $\mathrm{O}_{3}$ utilization efficiency is too low and the cost is high. The $\mathrm{KMnO}_{4}$ oxidation process is prone to excessive chromaticity. Recently, George P. Anipsitakis applied PMS to the degradation of organic matter, and AOP based on PMS has attracted more and more attention (George P. Anipsitakis et al.2020). PMS is an 
oxidant with extremely strong oxidizing ability. The activated PMS can generate a large amount of sulfate radicals $\left(\mathrm{SO}_{4} \cdot \mathrm{E}_{0}=2.5-3.1 \mathrm{~V}\right.$ )(Zhen Yuan Anipsitakis et al.2017) can directly attack organic matter and degrade organic matter into $\mathrm{CO}_{2}$ and $\mathrm{H}_{2} \mathrm{O}$. Transition metal activation, thermal activation, electrical activation, light activation and natural ore activation are the most common PMS activation methods(Joana F. Leal et al.2017; Qiang Gao et al.2021).Among the many activation methods, natural ore activated persulfate has the advantages of no additional energy, simple operation, low cost, and convenient material acquisition. At the same time, it can prevent a large number of toxic metal ions from entering the water body, which has been widely studied.Leiduo Lai and colleagues reported that vanadium-titanium magnetite as an activator of PMS showed excellent effects in degrading bisphenol A(Leiduo Lai et al.2021). Peng He and his team applied natural pyrite to the reduction of 2,4dichlorophenol (2,4-DCP) and $\mathrm{Cr}(\mathrm{VI})$, and within 120 minutes $76.2 \%$ of $2,4-\mathrm{DCP}$ and $80.1 \%$ of $\mathrm{Cr}(\mathrm{VI})$ is removed at the same time(Peng He et al.2021).Natural chalcopyrite (NCP) is a complex mineral containing multi-component metals ( $\mathrm{Cu}, \mathrm{Fe}, \mathrm{Ag}, \mathrm{Au}, \mathrm{Tl}, \mathrm{Se}, \mathrm{Te})$, of which $(\mathrm{Cu}, \mathrm{Fe}, \mathrm{S})$ are the main elements. In previous research, $\mathrm{CuFeS}_{2}$ synthesized in the laboratory was used to activate $\mathrm{H}_{2} \mathrm{O}_{2}, \mathrm{PMS}, \mathrm{PS}$ and showed excellent catalytic performance.However, as far as we know, NCP is usually used in metal smelting, and there are few studies on NCP activation of PMS.

In this paper, natural chalcopyrite was used to activate peroxymonosulfate, and the degradation efficiency of the NCP/PMS process on typical antiepileptic drugs was evaluated. In addition, reaction temperature, initial $\mathrm{pH}$, the NCP dosage, PMS dosage and inorganic anions on the degradation efficiency of the process were analyzed respectively. Finally, the contribution of free radicals in the degradation of carbamazepine under the optimal reaction conditions was studied, and then the influence of the addition of exogenous Fe on the NCP/PMS reaction system was investigated.

\section{Material And Methods}

\subsection{Experimental Materials}

Model pollutant carbamazepine (CBZ), peroxymonosulfate (PMS, $\left.\mathrm{KHSO}_{5} \cdot 0.5 \mathrm{KHSO}_{4} \cdot 0.5 \mathrm{~K}_{2} \mathrm{SO}_{4}\right) 5,5-$ dimethyl-1-pyrroline N-oxide (DMPO) and 2,2,6,6-tetramethyl-4-piperidinol (TEMP) were obtained from Aladdin (Shanghai, China).Chalcopyrite was purchased from Daye City, Hubei Province. Ethanol $\left(\mathrm{CH}_{3} \mathrm{CH}_{2} \mathrm{OH}\right)$ and tert-butanol $\left(\mathrm{C}_{4} \mathrm{H}_{10} \mathrm{O}, \mathrm{TBA}\right)$ were obtained from Kermel(Tianjin $₫$ China).Potassium bicarbonate $\left(\mathrm{KHCO}_{3}\right)$, sodium chloride $(\mathrm{NaCl})$, sodium sulfate $\left(\mathrm{Na}_{2} \mathrm{SO}_{4}\right)$, dipotassium hydrogen phosphate $\left(\mathrm{KH}_{2} \mathrm{PO}_{4}\right)$, copper sulfate $\left(5 \mathrm{CuSO}_{4} \cdot 5 \mathrm{H}_{2} \mathrm{O}\right), \mathrm{FeSO}_{4} \bullet 7 \mathrm{H}_{2} \mathrm{O}$, Sodium hydroxide $(\mathrm{NaOH})$, sulfuric acid $\left(\mathrm{H}_{2} \mathrm{SO}_{4}\right)$ and hydrochloric acid $(\mathrm{HCL})$ were obtained from Luoyang Chemical Reagent Factory(Henan,China)

Pyrite needs to be pretreated before use. Wash the ore with water and dilute hydrochloric acid to remove surface dust and impurities. The chalcopyrite is chiseled into small pieces and ground in a multifunctional grinder. The obtained product is washed repeatedly with distilled water and ethanol, and finally a clean chalcopyrite powder is obtained, which is dried and passed through a 200-mesh sieve. 


\subsection{Experimental procedures}

The catalysis experiments were carried out in a $250 \mathrm{~mL}$ open beaker containing $150 \mathrm{~mL} \mathrm{CBZ}(5 \mathrm{mg} / \mathrm{L})$ at a temperature of $298 \mathrm{~K}$ under constant mechanical stirring. First, pour carbamazepine solution into a beaker, then add a certain amount of NCP and PMS respectively, turn on the six stirrers, and start timing immediately.The CBZ solution was filtered by a $0.45 \mu \mathrm{m}$ filter (cellulose acetate membrane) and quickly placed into an ultraviolet-visible spectrophotometer at a wavelength of $285 \mathrm{~nm}$ for measurement(Shamima Begum et al.2018;Josué Daniel et al.2018)The measured absorbance was put into the standard curve and the degradation efficiency was calculateid.

$$
E=\frac{C_{\mathrm{t}}}{C_{0}} \times 100 \%
$$

Where $\mathrm{C}_{0}$ and $\mathrm{C}_{\mathrm{t}}$ are the $\mathrm{CBZ}$ concentration at the initial and time $\mathrm{t}$ (minutes), respectively. To ensure the credibility of the experiment, all experiments were conducted in parallel..

\subsection{Analytical methods}

The concentration of carbamazepine was measured by ultraviolet spectrophotometer(UV-3600冈Miputa囚 China).Scanning electron microscope (SEM, zeiss sigma 300) and energy spectrometer (EDS) were used to record the morphology and elemental composition of the NCP surface.The magnetic properties of the material were analyzed by hysteresis loop test (VSM,LAkeshoe 7404,).Besides,X-ray diffractometer(XRD,Philips,PANalytical B.V) was used to analyze elemental composition of NCP.X-ray photoelectron spectroscopy (XPS, AXIS Ultra DLD, Kratos Co.) was used to detecte the elemental composition and chemical oxidation state.Concentrations of various metal ions were monitored by inductively coupled plasma mass spectrometry (ICP-MS, NexION 350, PerkinElmer, USA).

\section{Results And Discussion}

\subsection{Characterization of NCP}

Observing the SEM Figure.1(a) shows that NCP is a kind of irregularly shaped block particles with rough surface and large specific surface area, which can provide more active sites for PMS activation. The NCP after the reaction is shown in Figure.1(c-d). It can be seen that the surface of the catalyst does not change much before and after the reaction, and it can still provide many active sites for activating PMS after repeated use. The result of energy dispersive spectroscopy『EDS『is shown in Figure.1(e). The EDS spectrum shows that the Fe content in the NCP is $33.02 \mathrm{Wt} \%$, the Cu content is $33.01 \mathrm{Wt} \%$, and the $\mathrm{S}$ content is $29.63 \mathrm{Wt} \%$. In addition, bulk elements NCP were analyzed by X-ray fluorescence spectrometer (XRF), and the main chemical elements are Fe (32.04 wt\%), Cu (28.93 wt\%) and S(33.4 wt\%) obtained, the results are basically consistent with the EDS analysis. It could be observed from Fig.1(f) that the XRD peaks with $2 \theta$ values of $29.35^{\circ}, 48.89^{\circ}$ and $57.87^{\circ}$ are the same as the standard XRD data of the 
standard CuFeS ${ }_{2}$ magnetite phase (PDF 83-0983)(Xiaotao Huang et al.2020;Xiangjian et al.2019).Considering the high content of Fe in NCP, the magnetic properties of a vibrating sample magnetometer are used to measure its magnetic properties. The resulting hysteresis loop is shown in Figure.1(g) below. It can be seen from the figure that the magnetic saturation of NCP is $1.5 \mathrm{emug}^{-1}$, exhibits paramagnetism at room temperature.

\subsection{The effect of different reaction systems on the degradation of CBZ}

In order to explore the influence of the NCP/PMS system on the degradation efficiency of CBZ, NCP, PMS and the NCP/PMS reaction system were added separately to degrade CBZ. According to research findings, chalcopyrite can react with $\mathrm{H}_{2} \mathrm{O}$ to generate $\mathrm{H}_{2} \mathrm{O}_{2}$ and $\mathrm{OH} \cdot$, but it is found through experiments that the removal rate of CBZ by using NCP alone is only $2.67 \%$, indicating that the oxidation and adsorption of NCP are difficult to degrade CBZ\Jasmeet Kaur et al.2017囚. At the same time, At the same time, the removal effect of PMS on CBZ is only $4.53 \%$. This may be because the oxidation ability of PMS is too weak $\left(E_{0}=1.82 \mathrm{~V}\right)$, which is not enough to destroy its chemical bonds CBZヌYanlong Sun et al.2020》. It can be concluded that without the addition of NCP catalyst, the degradation effect of PMS on CBZ is very limited. Under the NCP/PMS system, the removal rate of CBZ can reach $78.68 \%$ within 10 minutes of reaction, and slowly rises in the next 20 minutes, and the final removal rate remains at $82.34 \%$.

\subsection{The influence of NCP dosage on the reaction system}

The effect of different amounts of NCP on the degradation of CBZ is shown in Figure.2. Under the condition of $0.5 \mathrm{~g} / \mathrm{L}$ of PMS and no NCP, the degradation rate of CBZ is only $4.53 \%$.In contrast, in the presence of $0.5 \mathrm{~g} / \mathrm{L} \mathrm{NCP}$, the degradation efficiency of CBZ was significantly increased to $66.96 \%$.It can be seen that NCP can efficiently activate PMS to generate free radicals and degrade CBZ.As the dosage of NCP continues to increase to $1 \mathrm{~g} / \mathrm{L}$, the degradation efficiency of CBZ can be as high as $82.34 \%$, indicating that when the dosage of NCP increases from $0.5 \mathrm{~g} / \mathrm{L}$ to $1 \mathrm{~g} / \mathrm{L}$, the active sites of NCP increase, which activates PMS Improved efficiency and generate more free radicals. However, when the dosage of $\mathrm{NCP}$ is increased from $1.5 \mathrm{~g} / \mathrm{L}$, the degradation rate of CBZ decreases slightly. The main reason for this phenomenon is that the concentration of NCP in the solution is too high, which will quickly generate a large number of free radicals, causing $\mathrm{SO}_{4} \cdot$ and $\mathrm{OH}$ free radicals to quench each other, thereby reducing the number of free radicals in the solution. Therefore, the optimal amount of NCP was finally determined to be $1 \mathrm{~g} / \mathrm{L}$.

\subsection{The influence of PMS dosage on the reaction system}

The optimal dosage of NCP was determined to be $1 \mathrm{~g} / \mathrm{L}$, and the influence of the dosage of PMS on the reaction system was explored on the basis of the optimal dosage of NCP. The effect of different PMS dosage on the $\mathrm{CBZ}$ removal rate is shown in Figure 2(c). In the system without PMS, the degradation rate of CBZ is only $2.67 \%$. However, when the PMS dosage is only $0.05 \mathrm{~g} / \mathrm{L}$, the reaction rate increases rapidly and the CBZ removal rate reaches $49.67 \%$. This shows that NCP can efficiently activate PMS and quickly 
remove CBZ. When the amount of PMS is changed from $0.05 \mathrm{~g} / \mathrm{L}$ to $0.5 \mathrm{~g} / \mathrm{L}$, the CBZ removal rate increases steadily, and most of the CBZ is quickly removed within 10 minutes, indicating that the NCP activation of PMS is a fast process. When the amount of PMS was further increased to $0.6 \mathrm{~g} / \mathrm{L}$, the CBZ removal rate decreased instead. This phenomenon is attributed to the fact that the active site of NCP can fully activate when the amount of PMS is low, while the active site of NCP will be inhibited when the concentration of PMS is high. Compared with the traditional Fenton oxidation, NCP has a wider application in the degradation of carbamazepine.

The amount of PMS has a greater impact on the degradation kinetics of CBZ. Using Origin software to fit the degradation kinetics of NCP/PMS under optimized conditions, it can be concluded that the zero-order reaction, pseudo-first-order reaction and pseudo-second-order reaction kinetics correlation coefficients, respectively are $0.52591 \mathrm{~min}^{-1}, 0.6814 \mathrm{~min}^{-1}, 0.80176 \mathrm{~min}^{-1}$. The linear correlation of the degradation kinetics of NPC/PMS system is not ideal $\left(R^{2} \varangle 0.90\right)$. The reason for the poor correlation may be that under the optimal conditions of the NCP/PMS system, PMS is rapidly activated to produce $\mathrm{SO}_{4} \bullet$ in the initial stage of the reaction, leading to rapid degradation of CBZ molecules. Therefore, the author fitted the reaction kinetics with a PMS dosage of $0.05 \mathrm{~g} / \mathrm{L}$ as shown in Figure.2】e-f囚. Compared with the optimal conditions, the reaction rate decreased from $0.02892 \mathrm{~min}^{-1}$ to $0.00613 \mathrm{~min}^{-1}$, but the linear correlation increased from 0.80176 to $0.95463 \mathrm{~min}^{-1}$. Therefore, it can be considered that the CBZ degradation reaction of the NCP/PMS system follows the quasi-secondary reaction kinetics. It can be clearly seen from the kinetic analysis that the NCP/PMS degradation process of CBZ is divided into two stages, the degradation rate is very fast in the first 10 minutes, and the degradation rate is slow in the next 20 minutes.

\subsection{The influence of $\mathrm{PH}$ on the reaction system}

As we all know, differences in the distribution of electrons in molecules and $\mathrm{pH}$ generally affect the degradation efficiency of CBZ. In order to investigate the influence of $\mathrm{pH}$ on the reaction system, the removal effect of $\mathrm{CBZ}$ at $\mathrm{pH} 3,5,6.76,9$ and 11 was studied respectively.In order to avoid the use of buffers, the $\mathrm{pH}$ of the solution is adjusted by $0.1 \mathrm{M} \mathrm{HCL}$ and $0.1 \mathrm{M} \mathrm{NaOH}$. The study found that the removal rate was as high as $82.34 \%$ under the condition of $\mathrm{pH}=6.76$. This may be due to the low activation energy of PMS under neutral conditions, which can maintain a higher concentration and generate a large amount of $\mathrm{SO}_{4} \bullet$ to promote the degradation of CBZ. The slower reaction rate under acidic conditions is attributed to the faster decomposition of PMS in water冈Yanlong Sun et al.2020冈. On the other hand, under acidic conditions, chalcopyrite leaches a large amount of $\mathrm{Fe}^{3+}$ and $\mathrm{Cu}^{2+}$ to activate PMS faster, and produces high concentration of free radicals to quench. Under alkaline conditions, the content of $\mathrm{SO}_{4} \bullet$ in the original system decreases, and the content of $\mathrm{OH} \bullet$ increases. $\mathrm{OH} \bullet$ and $\mathrm{SO}_{4} \bullet$ will be quenched, resulting in a reduction in the content of free radicals and slowing down the degradation of $\mathrm{CBZ}^{\text {[27] }}$ (Sarita Dhaka et al.2017).

3.6 The influence of temperature on the reaction system 
In order to further evaluate the catalytic performance of NCP, the efficiency of NCP degrading CBZ at different temperatures was evaluated. When the reaction temperature was $298,303,308$, and $313 \mathrm{~K}$, the removal rate of CBZ was $81.03 \%, 82.34 \%, 78.39 \%$, and $76.75 \%$ after the reaction for 30 minutes. It can be seen from the figure.3 $\mathrm{\triangle a} \otimes$ that the degradation rate of $\mathrm{CBZ}$ at different temperatures is relatively close. The initial reaction rate increases when the reaction temperature is $308 \mathrm{~K}$ and $313 \mathrm{k}$, and the removal rate can reach $75 \%$ within 5 minutes, but the final degradation effect is slightly reduced. According to research, it has been found that this situation may occur in non-elementary reactions, which means that CBZ removal is a complicated process.During the reaction process, CBZ molecules are finally converted into degradation products through multi-step reactions, rather than directly converted into degradation products through simple reaction steps. The degradation of drugs and other pollutants in other AOPS systems is basically the same.Through the obtained pseudo-second-order kinetic rate constant and the Arrhenius equation(eq.2), the apparent activation energy of the NCP/PMS system to remove CBZ at different temperatures can be calculated. It is calculated that when the reaction temperature is 298,303 , 308 , and313K, the apparent activation energy of the CBZ removal reaction is $-18.61,-18.59,-18.18$ and $-17.80 \mathrm{Kj} \cdot \mathrm{mol}^{-1}$, which are all negative values.

$$
\begin{gathered}
\operatorname{Ln} k=-E_{a} / R T+\operatorname{Ln} A \\
\operatorname{Ln} \frac{k}{T}=-\frac{\Delta H}{R} \cdot \frac{1}{T}+\operatorname{Ln} \frac{k_{b}}{h}+\frac{\Delta S}{R} \\
\triangle \mathrm{G}=\triangle \mathrm{H}-\mathrm{T} \triangle \mathrm{S}
\end{gathered}
$$

Where $\mathrm{k}$ represents the kinetic reaction constant at temperature $\mathrm{T}$; Ea $\left(\mathrm{J} \cdot \mathrm{mol}^{-1}\right)$ is the apparent activation energy; $R$ is the molar gas constant equal to $8.314 \mathrm{j} \bullet(\mathrm{mol} \bullet \mathrm{K})^{-1} ; \mathrm{T}(\mathrm{K})$ represents the thermodynamic temperature; $A$ is the frequency factor; $\triangle H$ is the enthalpy change; $K_{b}$ is the Boltzmann constant $h-$ Planck's constant; $\triangle S$ is the entropy change.

Therefore, the CBZ removal reaction is a non-elemental reaction.In addition, the entropy change $(\triangle S)$ of the CBZ degradation reaction is calculated to be $-212.92 \mathrm{~J} \cdot \mathrm{mol}^{-1} \cdot \mathrm{K}^{-1}$ according to the pseudo-secondorder kinetic reaction rate constant and the Eying equation( eq.3).Under the reaction temperature of 298, 303,308 , and $313 \mathrm{~K}$, the enthalpy change $(\Delta H)$ of the reaction system is $-35.13,-35.57,-34.86$ and $-35.34 \mathrm{~kJ} \cdot \mathrm{mol}^{-1}$, respectively.Obviously, the enthalpy changes of the reaction at different temperatures are all negative, indicating that the CBZ removal reaction is an exothermic reaction, and increasing the temperature cannot effectively increase the reaction rate.According to the calculated enthalpy change and entropy change, the calculated Gibbs free energy in the reaction system is all positive, indicating that the reaction does not proceed spontaneously. In addition, the difference of $\Delta \mathrm{G}$ calculated (eq.4)at different temperatures is small, which can indicate that increasing the temperature cannot effectively increase the reaction rate.

3.7 The influence of inorganic anions in aqueous solution on the reaction system 
In this work, the influence of four typical inorganic anions on the degradation of CBZ in the NCP/PMS system was studied. As shown in Figure 4 below, it can be seen that during the reaction, $\mathrm{Cl}^{-}, \mathrm{HCO}_{3}{ }^{-}$, $\mathrm{H}_{2} \mathrm{PO}_{4}{ }^{-}, \mathrm{SO}_{4}{ }^{2-}$ all have an inhibitory effect on the degradation of $\mathrm{CBZ}$, and $\mathrm{HCO}_{3}{ }^{-}$has the strongest inhibitory effect.It can be concluded from Figure 4(a) that the degradation efficiency of CBZ in the presence of $2 \mathrm{mM} \mathrm{HCO}_{3}{ }^{-}(36.29 \%)$ is much lower than that without the addition of $\mathrm{HCO}_{3}{ }^{-}(82.34 \%)$, suggesting $\mathrm{HCO}_{3}{ }^{-}$has a significant inhibitory effect on the $\mathrm{CBZ}$ of the NCP/PMS system.The reason for this phenomenon is that the $\mathrm{pH}$ value of the $2 \mathrm{~mm} \mathrm{HCO}_{3}$ - solution increases, which weakens the electrostatic attraction between NCP, PMS and CBZ (Li Liu et al.2020). Research by Lei Zhou found that $\mathrm{OH} \bullet$ and $\mathrm{SO}_{4} \bullet$ can react with $\mathrm{Cl}^{-}$to generate chlorine free radicals with lower oxidation ability (Lei Zhou et al.2021). As shown in Figure.4(b), as the concentration of $\mathrm{Cl}^{-}$increased from $2 \mathrm{mM}$ to $5 \mathrm{mM}$, the degradation rate of CBZ decreased from $68.30 \%$ to $47.38 \%$. The experimental results are consistent with previous studies. As shown in the Figure.4(c), when $5 \mathrm{mM} \mathrm{H}_{2} \mathrm{PO}_{4}{ }^{-}$was introduced into the system, the degradation effect of CBZ was inhibited by approximately $11.81 \%$ compared to the optimal reaction conditions. This may be because $\mathrm{H}_{2} \mathrm{PO}_{4}{ }^{-}$can interact with $\mathrm{SO}_{4} \bullet$ and $\mathrm{OH} \bullet$ generated by the activation of PMS to form $\mathrm{H}_{2} \mathrm{PO}_{4}{ }^{\bullet}$, which has low oxidability (Fei Chen et al.2021). In addition, studies have shown that phosphate can reduce the utilization of iron in the material in the process of activating PMS, which will weaken the efficiency of the material in activating PMS (Gui-Xiang Huang et al.2017).In summary, the inhibitory effect of inorganic anions on CBZ is mainly achieved through the competitive consumption of free radicals in the system, where the strength of the inhibitory effect is $\mathrm{HCO}_{3}{ }^{-}>\mathrm{Cl}^{-}>\mathrm{H}_{2} \mathrm{PO}_{4}>\mathrm{SO}_{4}{ }^{2-}$.

\subsection{Stability of the catalyst}

Stability is a necessary condition for a catalyst to be recycled (M. L. ArunaKumari and L. Gomathi Devi et al.2015). In order to evaluate the repeatability of the catalyst, four repeated experiments were carried out on NCP.The results of repeated experiments are shown in Figure.5. We can observe that the degradation efficiency of CBZ decreases slightly after each use. After four recycling experiments, the degradation rate of CBZ drops from $82.34 \%$ to $50.21 \%$. By observing Figure. 1 (c-d), it can be seen that the surface of the NCP after use becomes rougher, and the pores of the NCP are blocked by the organic matter generated during the degradation of $\mathrm{CBZ}$, which may be the cause of the deterioration of the NCP effect.

\subsection{The formation of active oxide species in the NCP/PMS system}

As we all know, PMS can be activated to generate $\mathrm{OH} \bullet$ or SO4• and degrade organic compounds. Ethanol $(\mathrm{EtOH})$ and tert-butanol (TBA) are widely used as $\mathrm{SO}_{4} \bullet$ and $\mathrm{OH} \bullet$ scavengers (Yanbin Wang et al.2018;Peng Zhou et al.2018).This method is based on the difference in reactivity and reaction rate between the free radical species produced in the system and specific alcohols. The second order rate constants of EtOH and $\mathrm{OH} \bullet$ and $\mathrm{SO}_{4} \bullet$ are $\left(1.6-7.7 \times 10^{7}\right) \mathrm{L} /(\mathrm{mol} \bullet \mathrm{s})$ and $\left(1.2-2.8 \times 10^{9}\right) \mathrm{L} /(\mathrm{mol} \bullet \mathrm{s})$, while TBA and $\mathrm{OH} \bullet$ ( The second order reaction rate constant of $\left.3.8 \times 10^{8}-1.0 \times 10^{9}\right) \mathrm{L} /(\mathrm{mol} \bullet \mathrm{s})$ is tert-butanol and $\mathrm{SO}_{4} \cdot\left(4 \times 10^{5}-9.1 \times 10^{5}\right) \mathrm{L} /(\mathrm{mol} \bullet \mathrm{s})$. Therefore, in the NCP/PMS system, the type of free radicals produced in 
the system can be judged according to the degree of inhibition of CBZ degradation by ethanol and tertbutanol.Obviously, EtOH can quench both $\mathrm{SO}_{4} \bullet$ and $\mathrm{OH} \bullet$ at the same time, while TBA only serves as a trapping agent for $\mathrm{OH} \bullet$ (Chaoqun Tan et al.2012).In order to avoid changes in solution concentration caused by the addition of the capture agent, all curves are blanked by subtracting the capture agent itself.The results of radical quenching are shown in Figure.5(a).At the TBA concentration of $0.1 \mathrm{M}$ and $0.5 \mathrm{M}$,we observed that the degradation efficiency of CBZ decreased from $82.34 \%$ to $69.89 \%, 68.54 \%$. The inhibitory effect on the reaction system is not obvious, indicating that only a small amount of $\mathrm{OH} \bullet$ is produced in the system. However,at the $\mathrm{EtOH}$ concentration of $0.1 \mathrm{M}$ and $0.2 \mathrm{M}$,the removal rate of $\mathrm{CBZ}$ is only $30.56 \%$ and $18.10 \%$, suggesting that the system contains a large amount of $\mathrm{SO}_{4}{ }^{\circ}$, which is the main active species in the system, while $\mathrm{OH} \bullet$ and other active species only produce a small part of the effect.

In order to directly evaluate the free radicals generated in the NCP/PMS system, DMPO is used to capture free radicals to investigate whether the reaction produces $\mathrm{SO}_{4} \cdot$ and $\mathrm{OH} \bullet$. Add DMPO to the reaction solution and detect the EPR spectrum, which is used to determine the free radicals in the reaction. As shown in figure.5(b), typical $\mathrm{OH} \bullet$ and $\mathrm{SO}_{4} \bullet$ spectra are detected in the NCP/PMS of the DMPO system, and the signal intensity is high, indicating that a large amount of $\mathrm{OH} \bullet$ and $\mathrm{SO}_{4} \bullet$ are produced in the solution during this process.In addition, research by Qin Qingdong et al.(2021) showed that singlet oxygen $\left({ }^{1} \mathrm{O}_{2}\right)$ is usually present in activated PMS systems, and 2,2,6,6-tetramethyl-4-piperidinol (TEMP) is typical The spin trap probe can trap ${ }^{1} \mathrm{O}_{2}$ to form a TEMPO adduct. In order to verify the existence of ${ }^{1} \mathrm{O}_{2}$ in the system, TEMP was added to the reaction solution to obtain the EPR spectrum. As shown in figure.5(b), the characteristic signal of TEMPO with an intensity ratio of 1:1:1 can be clearly expressed, so ${ }^{1} \mathrm{O}_{2}$ is also one of the activated species in the NCP/PMS system (Haiyuan Chi et al.2021; Jinhong Fan et al.2019).

3.10 The role of iron and copper and the influence of additional iron sources on the system

The reaction system was further analyzed by ICP-MS, and the result is shown in Figure.7, which shows that a small amount of $\mathrm{Fe}$ and $\mathrm{Cu}$ elements are dissolved in the reaction system. Then, in order to determine the influence of $\mathrm{Fe}^{3+}$ and $\mathrm{Cu}^{2+}$ on the NCP/PMS system, $5 \mathrm{mg} / \mathrm{LCu}^{2+}$ and $\mathrm{Fe}^{3+}$ were introduced into the NCP/PMS system. The result is shown in Figure.7囚b囚, the removal rate of the system increased from $82.34 \%$ to $86.29 \%, 84.90 \%$. The study by Jiali Peng et al.(2020)showed that this phenomenon may be related to the cycle of $\mathrm{Fe}^{3+}$ and $\mathrm{Cu}^{2+} \cdot \mathrm{S}_{2}{ }^{2-}$ as an electron donor can reduce $\mathrm{Cu}^{2+}$ and $\mathrm{Fe}^{3+}$ to $\mathrm{Cu}^{+}$and $\mathrm{Fe}^{2+}$, generating more active sites System promotes the activation of PMS.In order to better evaluate the influence of $\mathrm{Cu}^{2+}$ and $\mathrm{Fe}^{3+}$ on the reaction system, XPS was used to analyze the NCP before and after the reaction. The high-resolution spectra of Fe2p and Cu2p in NCP before and after the reaction are shown in Figure.7(c-d).In the Fe2p spectrum, the characteristic peaks with binding energies of $710.01 \mathrm{eV}$ and $711.46 \mathrm{eV}$ represent the presence of $\mathrm{Fe}^{2+}$ and $\mathrm{Fe}^{3+}$, respectively (Mark C. Biesinger et al.2012). By calculating the deconvolution and peak area, it can be concluded that the ratio of $\mathrm{Fe}^{2+}$ on the surface of NCP before and after the reaction decreased from $61.3 \%$ to $56.08 \%$, indicating that part of $\mathrm{Fe}^{2+}$ on the 
surface of NCP was converted to $\mathrm{Fe}^{3+}$ during the degradation of CBZ. In the same way, it can be seen that Cu2 $\mathrm{p}^{1 / 2}$ and Cu2 $\mathrm{p}^{3 / 2}$ appear at binding energies of $952.38 \mathrm{eV}$ and $932.56 \mathrm{eV}$, respectively (J. P. Espinós et al.2002). Similarly, the proportion of $\mathrm{Cu}^{2+}$ dropped from $50.30 \%$ to $48.23 \%$ after the reaction.

Although the degradation efficiency of $\mathrm{Cu}^{2+}$ and $\mathrm{Fe}^{3+} \mathrm{CBZ}$ has been partly improved by the introduction of $\mathrm{Cu}^{2+}$ and $\mathrm{Fe}^{3+} \mathrm{CBZ}$, new heavy metal pollution has also been introduced. The author found that the removal rate of CBZ degraded by the NCP/PMS system increased from $82.34 \%$ to $90.73 \%$ in the presence of $0.15 \mathrm{~g} / \mathrm{L}$ exogenous Fe. On the one hand, the addition of Fe source can replace $\mathrm{Cu}^{2+}$ and $\mathrm{Fe}^{3+}$ in the system and reduce the leaching of harmful metals in water. On the other hand, zero-valent Fe can directly activate PMS and degrade CBZ.

\subsection{Mechanism analysis}

After the above analysis, the possible activation mechanism in the NCP/PMS system is speculated. As shown in Figure 8, NCP and PMS have a certain adsorption and oxidation effect on CBZ molecules, but this part of the effect is very weak.Obviously, it can be concluded that the reason for the efficient degradation of $C B Z$ in the NCP/PMS reaction system is mainly the degradation of CBZ by the active substance.First, when NCP and PMS are added to the reaction solution, $\mathrm{Fe}^{2+}$ and $\mathrm{Cu}^{+}$on the surface of $\mathrm{NCP}$ will activate $\mathrm{PMS}$ to produce $\mathrm{OH}$ and $\mathrm{SO}_{4} \bullet$ which can directly degrade $\mathrm{CBZ}$ into $\mathrm{H}_{2} \mathrm{O}$ and $\mathrm{CO}_{2}$. At the same time, $\mathrm{Fe}^{2+}$ and $\mathrm{Cu}^{+}$on the surface of NCP lose electrons and are oxidized to $\mathrm{Fe}^{3+}$ and $\mathrm{Cu}^{2+}$. On the other hand, NCP reacts with PMS to produce a small amount of ${ }^{1} \mathrm{O}_{2}$, which has a certain effect on the degradation of carbamazepine (Ningruo Wang et al.2020). In addition, the sulfur species on the surface of the NCP can promote the reduction of $\mathrm{Fe}^{3+}$ and $\mathrm{Cu}^{2+}$, further improving the catalytic efficiency of the system. The specific reaction formula is shown in eq(5-13).

$$
\begin{aligned}
& \mathrm{Fe}^{2+}+\mathrm{HSO}_{5}{ }^{-} \rightarrow \mathrm{Fe}^{3+}+\mathrm{SO}_{4} \bullet+\mathrm{OH}^{-} \quad \text { \5】 } \\
& \mathrm{Fe}^{2+}+\mathrm{HSO}_{5}{ }^{-} \rightarrow \mathrm{Fe}^{3+}+\mathrm{OH} \bullet+\mathrm{SO}_{4}{ }^{2-} \quad \text { \66 } \\
& \mathrm{Cu}^{+}+\mathrm{HSO}_{5}{ }^{-} \rightarrow \mathrm{Cu}^{2+}+\mathrm{SO}_{4} \bullet+\mathrm{OH}^{-} \quad \text { \7》 } \\
& \mathrm{Cu}^{+}+\mathrm{HSO}_{5}{ }^{-} \rightarrow \mathrm{Cu}^{2+}+\mathrm{OH} \bullet+\mathrm{SO}_{4}{ }^{2-} \quad \nabla 8 \square \\
& \mathrm{SO}_{4}{ }^{--}+\mathrm{H}_{2} \mathrm{O} \rightarrow \mathrm{HSO}_{4}{ }^{-}+\mathrm{OH} \bullet \quad \square 98 \\
& \mathrm{HSO}_{5}{ }^{-}+\mathrm{NCP} \rightarrow \mathrm{NCP} \bullet+\mathrm{SO}_{5}{ }^{-}+\mathrm{H}^{+} \quad \text { Q10区 } \\
& 2 \mathrm{SO}_{5}{ }^{-}+\mathrm{NCP} \cdot \rightarrow \mathrm{NCP}+2 \mathrm{SO}_{4}{ }^{2-}+{ }^{1} \mathrm{O}_{2} \quad \otimes 11 \rrbracket \\
& \mathrm{S}^{2-}+\mathrm{Fe}^{3+} \rightarrow \mathrm{Fe}^{2+}+\mathrm{S}_{2}{ }^{2-}
\end{aligned}
$$


$\mathrm{S}^{2-}+\mathrm{Cu}^{2+} \rightarrow \mathrm{Cu}^{+}+\mathrm{S}_{2}^{2-}$

$\mathrm{Cu}^{+}+\mathrm{Fe}^{3+} \rightarrow \mathrm{Fe}^{2+}+\mathrm{Cu}^{2+}$

\14囚

\section{Conclusion}

In this work, NCP was used as an activator of PMS to degrade CBZ. The experimental results showed that under the conditions of $5 \mathrm{mg} / \mathrm{LCBZ}, 1 \mathrm{~g} / \mathrm{LNCP}, 0.5 \mathrm{~g} / \mathrm{L} \mathrm{PMS}$ and $\mathrm{PH}=6.76,82.34 \%$ of $\mathrm{CBZ}$ was degraded within $30 \mathrm{~min}$. In addition, the optimal reaction temperature is $25^{\circ} \mathrm{C}$, and increasing the temperature cann't effectively increase the reaction rate. Through further analysis,the results show that the main active species in the NCP/PMS system are $\mathrm{SO}_{4} \bullet, \mathrm{OH} \bullet$ and ${ }^{1} \mathrm{O}_{2}$, and the contribution rate of $\mathrm{SO}_{4} \bullet$ can reach more than $80 \%$.Analysis based on XRF and XPS shows that Fe and Cu elements in NCP play an important role in the activation of PMS. Finally, the study also found that NCP and Fe(ZVI) may have a certain synergistic effect. The degradation efficiency of CBZ in the NCP/PMS system was only $82.34 \%$ within 30 minutes, and the degradation efficiency increased to $90.7 \%$ after adding $0.15 \mathrm{~g} / \mathrm{L} \mathrm{Fe}^{0}$.This research broadens the application range of natural minerals in the field of environmental catalysis, and is of great significance to the application of natural minerals to actual water bodies.

\section{Declarations}

\section{Funding}

This work was financially supported by the National Water Pollution Control and Treatment Science and Technology Major Project (NO. 2017ZX07602-001-002)

\section{Authors' contributions}

All authors contributed to the study conception and design. Material preparation, data collection and analysis were performed by GaoYang Xi, XuXun Chen, Xuhang Zhangand Yu Xing. The first draft of the manuscript was written by Zhengguang $\mathrm{He}$ and all authors commented on previous versions of the manuscript. All authors read and approved the final manuscript.

\section{Disclosure}

The authors certify that this manuscript is the original work of the authors, all data collected during the study are presented in this manuscript, and no data from the study has been or will be published elsewhere separately

\section{Availability of data and material}

The datasets used or analysed during the current study are available from the corresponding author on reasonable request. 


\section{Ethical Approval}

Not applicable.

\section{Consent to participate}

Not applicable.

\section{Consent to publish}

All authors reviewed and approved the manuscript for publication.

\section{Conflict of interest}

The authors declare no conflict of interest.

\section{References}

C. G.Daughton,T.A.Ternes Pharmaceuticals and personal care products in the environment: agents of subtle change? Environ. Health Perspect,107(1999), pp.907-938https://doi.org/10.1289/ehp.99107s6907

Chaoqun Tan, Naiyun Gao, Yang Deng, Na An, Jing Deng,Heat-activated persulfate oxidation of diuron in water,Chemical Engineering Journal,Volume 203,2012,Pages 294-

300,https://doi.org/10.1016/j.cej.2012.07.005

Fei Chen, Lian-Lian Liu, Jie-Jie Chen, Wen-Wei Li, You-Peng Chen, Ying-Jie Zhang, Jing-Hang Wu, ShuChuan Mei, Qi Yang, Han-Qing Yu,Efficient decontamination of organic pollutants under high salinity conditions by a nonradical peroxymonosulfate activation system, Water Research,Volume 191,2021,116799,https://doi.org/10.1016/j.watres.2020.116799

George P. Anipsitakis and Dionysios D. Dionysiou,Degradation of Organic Contaminants in Water with Sulfate Radicals Generated by the Conjunction of Peroxymonosulfate with Cobalt.Environmental Science \& Technology2003.37(20), 4790-4797,https://doi.org/10.1021/es0263792

Guangfei Yu, Yuxian Wang, Hongbin Cao, He Zhao, and Yongbing Xie,Reactive Oxygen Species and Catalytic ActiveSites in Heterogeneous Catalytic Ozonation for Water Purification,Environmental Science\& Technology 2020 54(10), 5931-5946,https://doi.org/10.1021/acs.est.0c00575

Gui-Xiang Huang, Chu-Ya Wang, Chuan-Wang Yang, Pu-Can Guo, and Han-Qing Yu,Degradation of Bisphenol A by Peroxymonosulfate Catalytically Activated with $\mathrm{Mn}_{1.8} \mathrm{Fe}_{1.2} \mathrm{O}_{4}$ Nanospheres: Synergism between Mn and Fe,Environmental Science \& Technology2017 51(21), 1261112618,https://doi.org/10.1021/acs.est.7b03007 
Haiyuan Chi, Jinquan Wan, Xiaoxia Zhou, Jian Sun, Bing Yan,Fe@C activated peroxymonosulfate system for effectively degrading emerging contaminants: Analysis of the formation and activation mechanism of Fe coordinately unsaturated metal sites,Journal of Hazardous Materials,Volume 419,2021,126535,https://doi.org/10.1016/j.jhazmat.2021.126535

J. P. Espinós, J. Morales, A. Barranco, A. Caballero, J. P. Holgado, and A. R. González-Elipe,Interface Effects for $\mathrm{Cu}, \mathrm{CuO}$, and $\mathrm{Cu}_{2} \mathrm{O}$ Deposited on $\mathrm{SiO}_{2}$ and $\mathrm{ZrO}_{2}$. XPS Determination of the Valence State of Copper in $\mathrm{Cu} / \mathrm{SiO}_{2}$ and $\mathrm{Cu} / \mathrm{ZrO}_{2}$ Catalysts, The Journal of Physical Chemistry B2002106(27), 69216929,https://doi.org/10.1021/jp014618m

Jasmeet Kaur, Martin A. Schoonen,Non-linear hydroxyl radical formation rate in dispersions containing mixtures of pyrite and chalcopyrite particles,Geochimica et Cosmochimica Acta,Volume 206,2017,Pages 364-378,https://doi.org/10.1016/j.gca.2017.03.011

Jean-Rene Thelusmond, Emily Kawka, Timothy J. Strathmann, Alison M. Cupples,Diclofenac, carbamazepine and triclocarban biodegradation in agricultural soils and the microorganisms and metabolic pathways affected,Science of The Total Environment,Volumes 640-641,2018,Pages 13931410,https://doi.org/10.1016/j.scitotenv.2018.05.403

Jiali Peng, Hongyu Zhou, Wen Liu, Zhimin Ao, Haodong Ji, Yang Liu, Shijun Su, Gang Yao, Bo Lai,Insights into heterogeneous catalytic activation of peroxymonosulfate by natural chalcopyrite: $\mathrm{pH}$-dependent radical generation, degradation pathway and mechanism,Chemical Engineering Journal,Volume 397,2020,125387,https://doi.org/10.1016/j.cej.2020.125387

Jian Xu, Lei Li, Changsheng Guo, Yuan Zhang, Wei Meng,Photocatalytic degradation of carbamazepine by tailored BiP04: efficiency, intermediates and pathway,Applied Catalysis B: Environmental,Volumes 130-131,2013,Pages 285-292,https://doi.org/10.1016/j.apcatb.2012.11.013

Jianlong Wang, Shizong Wang,Removal of pharmaceuticals and personal care products (PPCPs) from wastewater: A review,Journal of Environmental Management,Volume 182,2016,Pages 620640,https://doi.org/10.1016/j.jenvman.2016.07.049

Jinhong Fan, Hehe Qin, Simin Jiang,Mn-doped g-C3N4 composite to activate peroxymonosulfate for acetaminophen degradation: The role of superoxide anion and singlet oxygen,Chemical Engineering Journal,Volume 359,2019,Pages 723-732,https://doi.org/10.1016/j.cej.2018.11.165

Joana F. Leal, Sandra M. A. Cruz,Bernardo T. A. Almeida,Valdemar I. Esteves, Paula A. A. P. Marques and Eduarda B.H. Santos, $\mathrm{TiO}_{2}-\mathrm{rGO}$ nanocomposite as an efficient catalyst to photodegrade formalin in aquaculture's waters, under solar light, Environ. Sci: Water Res. Technol, 2020, 6, 1018,https://doi.org/10.1039/C9EW00950G

Josué Daniel García-Espinoza, Petia Mijaylova-Nacheva, Martha Avilés-Flores,Electrochemical carbamazepine degradation: Effect of the generated active chlorine, transformation pathways and 
toxicity,Chemosphere,Volume 192,2018,Pages 142-

151,https://doi.org/10.1016/j.chemosphere.2017.10.147

Junxue Wu, Bin Wang, Giovanni Cagnetta, Jun Huang, Yujue Wang, Shubo Deng, Gang Yu,Nanoscale zero valent iron-activated persulfate coupled with Fenton oxidation process for typical pharmaceuticals and personal care products degradation,Separation and Purification Technology,Volume 239,2020,116534,https://doi.org/10.1016/j.seppur.2020.116534

Lei Zhou, Xuerui Yang, Yuefei Ji, Jie Wei,Sulfate radical-based oxidation of the antibiotics sulfamethoxazole, sulfisoxazole, sulfathiazole, and sulfamethizole: The role of five-membered heterocyclic rings,Science of The Total Environment,Volume 692,2019,Pages 201208,https://doi.org/10.1016/j.scitotenv.2019.07.259

Leiduo Lai, Hongyu Zhou, Bo Lai,Heterogeneous degradation of bisphenol A by peroxymonosulfate activated with vanadium-titanium magnetite: Performance, transformation pathways and mechanism,Chemical Engineering Journal,Volume 349,2018,Pages 633645,https://doi.org/10.1016/j.cej.2018.05.134

Li Liu, Yunong Li, Wei Li, Ruixue Zhong, Yeqing Lan, Jing Guo,The efficient degradation of sulfisoxazole by singlet oxygen $\left({ }^{1} \mathrm{O}_{2}\right)$ derived from activated peroxymonosulfate (PMS) with $\mathrm{Co}_{3} \mathrm{O}_{4}{ }^{-}$ $\mathrm{SnO}_{2} / \mathrm{RSBC}$,Environmental Research,Volume 187,2020,109665,https://doi.org/10.1016/j.envres.2020.109665

Liu, K., et al. "Degradation and Mineralization of Carbamazepine Using an Electro-Fenton Reaction Catalyzed by Magnetite Nanoparticles Fixed on an Electrocatalytic Carbon Fiber Textile Cathode." Environmental Science \& Technology 52(21): 12667-12674.https://doi.org/10.1021/acs.est.8b03916

M. Checa, F. J. Beltrán, F. J. Rivas a and E. Corderob,On the role of a graphene oxide/titania catalyst, visible LED and ozone in removing mixtures of pharmaceutical contaminants from water and wastewate,Environ. Sci.: Water Res. Technol., 2020, 6, 2352,https://doi.org/10.1039/D0EW00276C

M. L. ArunaKumari and L. Gomathi Devi ${ }^{\star}$,New insights into the origin of the visible light photocatalytic activity of $\mathrm{Fe}(\mathrm{III})$ porphyrin surface anchored $\mathrm{TiO}_{2}$,Environ. Sci.: Water Res. Technol., 2015, 1, 177

Majid Kermani,Farzad Mohammadi,Babak Kakavandi,Ali Esrafili,Zeinab Rostamifasih. Simultaneous catalytic degradation of 2,4-D and MCPA herbicides using sulfate radical-based heterogeneous oxidation over persulfate activated by natural hematite $\left(\mathrm{a}-\mathrm{Fe}_{2} \mathrm{O}_{3} / \mathrm{PS}\right)$, Journal of Physics and Chemistry of Solids,Volume 117,2018,Pages 49-59,https://doi.org/10.1016/j.jpcs.2018.02.009

Mark C. Biesinger, Brad P. Payne, Andrew P. Grosvenor, Leo W.M. Lau, Andrea R. Gerson, Roger St.C. Smart,Resolving surface chemical states in XPS analysis of first row transition metals, oxides and 
hydroxides: Cr, Mn, Fe, Co and Ni,Applied Surface Science,Volume 257, Issue 7,2011,Pages 2717-2730,me 239,2020,116534,https://doi.org/10.1016/j.apsusc.2010.10.051

Nakorn Suriyanon, Patiparn Punyapalakul, Chawalit Ngamcharussrivichai,Mechanistic study of diclofenac and carbamazepine adsorption on functionalized silica-based porous materials,Chemical Engineering Journal,Volume 214,2013,Pages 208-218,https://doi.org/10.1016/j.cej.2012.10.052

Ningruo Wang, Jian Zhang, Peng Zhou, Yongli Zhang, Wei Li, Feng Cheng, Zhicheng Pan, Yang Liu, Bo Lai,Iron molydate catalyzed activation of peroxymonosulfate for bisphenol AF degradation via synergetic non-radical and radical pathways,Science of The Total Environment,Volume 797,2021,149151,https://doi.org/10.1016/j.scitotenv.2021.149151

Peng He, Jianyu Zhu, Yaozong Chen, Fang Chen, Jinglei Zhu, Mengfei Liu, Ke Zhang, Min Gan,Pyriteactivated persulfate for simultaneous 2,4-DCP oxidation and $\mathrm{Cr}(\mathrm{VI})$ reduction,Chemical Engineering Journal,Volume 406,2021,126758,https://doi.org/10.1016/j.cej.2020.126758

Peng Zhou, Jing Zhang, Yongli Zhang, Gucheng Zhang, Wenshu Li, Chenmo Wei, Juan Liang, Ya Liu, Shihu Shu,Degradation of 2,4-dichlorophenol by activating persulfate and peroxomonosulfate using micron or nanoscale zero-valent copper,Journal of Hazardous Materials,Volume 344,2018,Pages 12091219,https://doi.org/10.1016/j.jhazmat.2017.11.023

Qiang Gao,Guanshuai Wang,Yiren Chen,Utilizing cobalt-doped materials as heterogeneous catalysts to activate peroxymonosulfate for organic pollutant degradation: a critical review Environ. Sci.: Water Res. Technol., 2021,7, 1197-1211

Qingdong Qin, Ting Liu, Jiaxuan Zhang, Rui Wei, Shijie You, Yan Xu,Facile synthesis of oxygen vacancies enriched $\mathrm{a}-\mathrm{Fe}_{2} \mathrm{O}_{3}$ for peroxymonosulfate activation: A non-radical process for sulfamethoxazole degradation,Journal of Hazardous Materials, Volume 419,2021,126447,https://doi.org/10.1016/j.jhazmat.2021.126447

Sarita Dhaka, Rahul Kumar, Moonis Ali Khan, Ki-Jung Paeng, Mayur B. Kurade, Sun-Joon Kim, Byong-Hun Jeon,Aqueous phase degradation of methyl paraben using UV-activated persulfate method,Chemical Engineering Journal,Volume 321,2017,Pages 11-19,https://doi.org/10.1016/j.cej.2017.03.085

Shamima Begum, M. Ahmaruzzaman,CTAB and SDS assisted facile fabrication of $\mathrm{SnO}_{2}$ nanoparticles for effective degradation of carbamazepine from aqueous phase: A systematic and comparative study of their degradation performance,Water Research,Volume 129,2018,Pages 470485,https://doi.org/10.1016/j.watres.2017.11.031

Xiangjian Xu, Dingding Tang, Jianhua Cai, Beidou Xi, Yan Zhang, Liu Pi, Xuhui Mao,Heterogeneous activation of peroxymonocarbonate by chalcopyrite $\left(\mathrm{CuFeS}_{2}\right)$ for efficient degradation of 2,4dichlorophenol in simulated groundwater,Applied Catalysis B: Environmental,Volume 251,2019,Pages 273-282,https://doi.org/10.1016/j.apcatb.2019.03.080 
Xiaotao Huang, Tonghe Zhu, Weijian Duan, Sheng Liang, Ge Li, Wei Xiao,Comparative studies on catalytic mechanisms for natural chalcopyrite-induced Fenton oxidation: Effect of chalcopyrite type,Journal of Hazardous Materials,Volume 381,2020,120998,https://doi.org/10.1016/j.jhazmat.2019.120998

Y.F. Rao, Liang Qu, Haisong Yang, W. Chu,Degradation of carbamazepine by Fe(II)-activated persulfate process,Journal of Hazardous Materials,Volume 268,2014,Pages 23-

32,https://doi.org/10.1016/j.jhazmat.2014.01.010

Yanbin Wang, Man Liu, Xu Zhao, Di Cao, Tao Guo, Bo Yang,Insights into heterogeneous catalysis of peroxymonosulfate activation by boron-doped ordered mesoporous carbon,Carbon,Volume 135,2018,Pages 238-247,https://doi.org/10.1016/j.carbon.2018.01.106

Yanlong Sun, Hongbin Xie, Chengzhi Zhou, Yuandong Wu, Mengjie Pu, Junfeng Niu,The role of carbonate in sulfamethoxazole degradation by peroxymonosulfate without catalyst and the generation of carbonate racial,Journal of Hazardous Materials,Volume 398,2020,122827,https://doi.org/10.1016/j.jhazmat.2020.122827

Yi Shi, Yan Zhang, Yanru Cui, Jianrong Shi, Xiaoyan Meng, Jingyi Zhang, Hua He,Magnetite nanoparticles modified $\beta$-cyclodextrin PolymerCoupled with $\mathrm{KMnO} 4$ oxidation for adsorption and degradation of acetaminophen,Carbohydrate Polymers,Volume 222,2019,114972,https://doi.org/10.1016/j.carbpol.2019.114972

Yongjun Zhang, Sven-Uwe Geißen,Carmen Gal, Carbamazepine and diclofenac: Removal in wastewater treatment plants and occurrence in water bodies, Chemosphere,Volume 73, Issue 8,2008, Pages 11511161,https://doi.org/10.1016/j.chemosphere.2008.07.086

Zhen Yuan, Minghao Sui,* Bojie Yuan, Pan Li, ${ }^{\star}$ Jingyu Wang, Jie Qin and Guangyi Xu,Degradation of ibuprofen using ozone combined with peroxymonosulfate. Environ. Sci.: Water Res. Technol, 2017, 3, 960,https://doi.org/10.1039/C7EW00174F

\section{Figures}




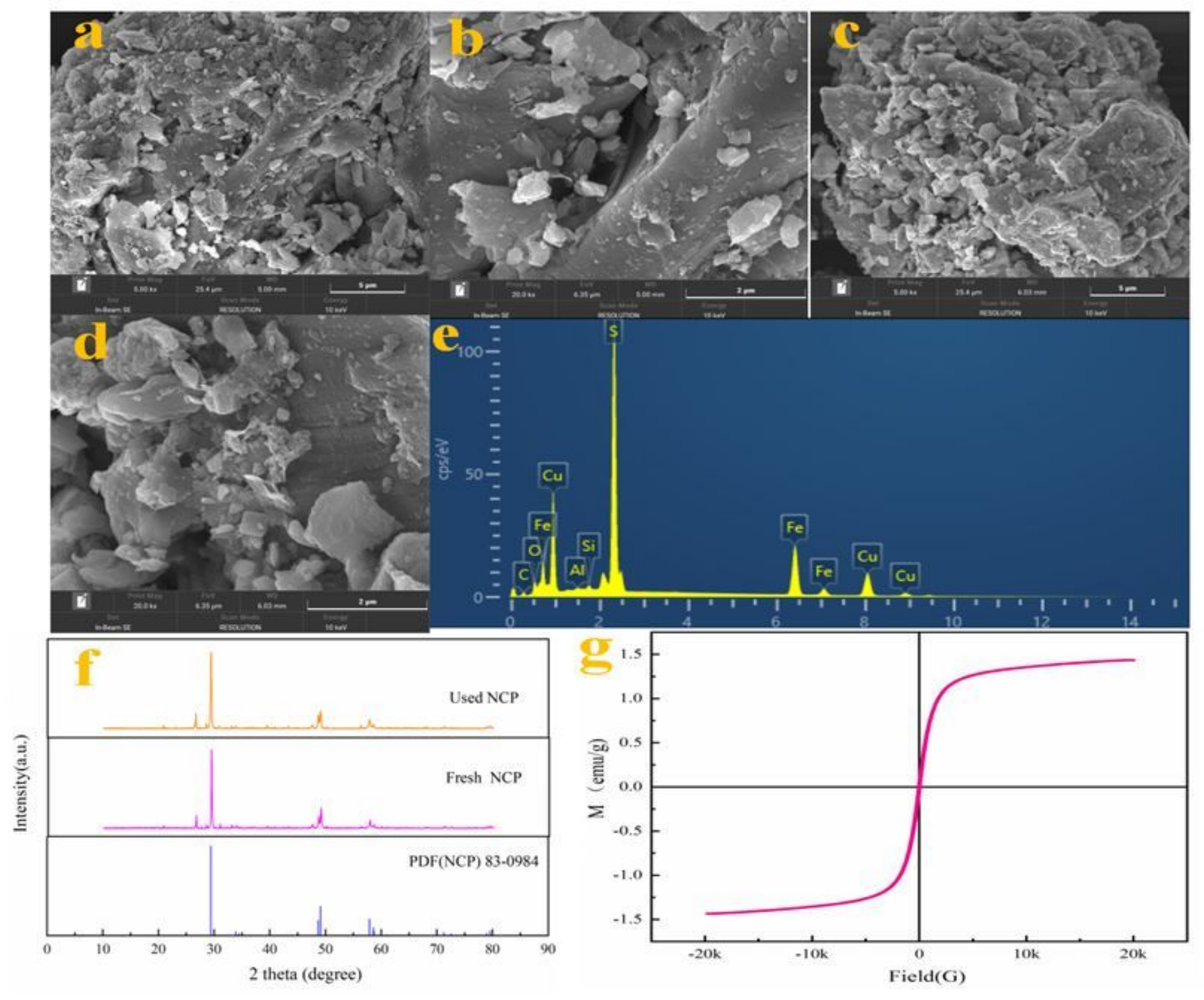

Figure 1

Characterization of NCP: (a) 5KX before using NCP(SEM image); (b) 20KX before using NCP(SEM image); (c) $5 \mathrm{KX}$ after using NCP;(SEM image) (d) 20KX after using NCP;(SEM image) (e) EDS image; (f)XRD pattern of $\mathrm{CuFeS}_{2} ;(\mathrm{g})$ magnetization hysteresis loop of NCP. 

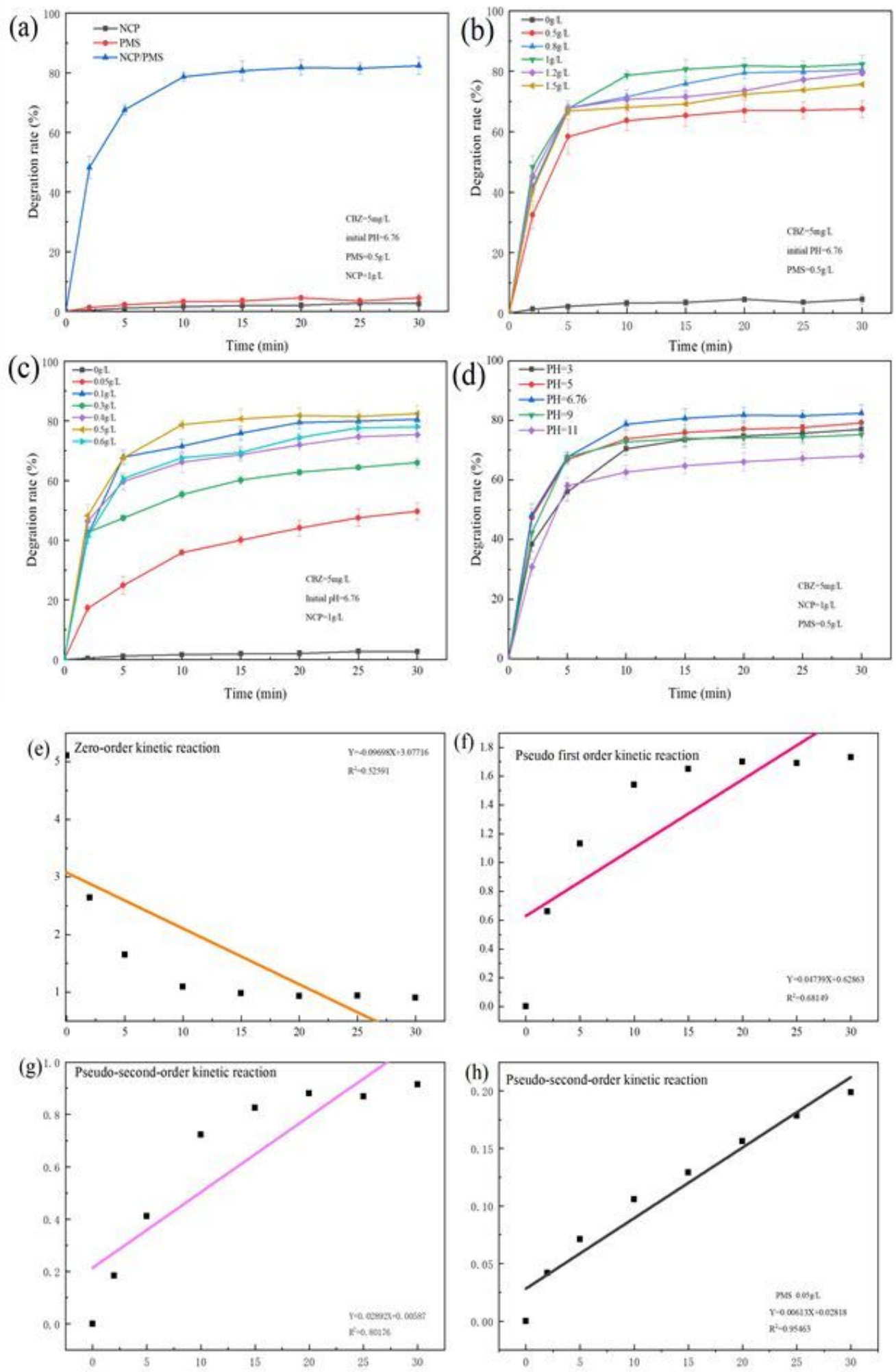

Figure 2

The influence of different reaction conditions: (a)Different reaction systems (b)The influence of NCP dosage on the reaction system (c)The influence of PMS dosage on the reaction system (d)The influence of $\mathrm{PH}$ on the reaction system (e)Zero-order kinetic reaction ( $\mathrm{f}$ )Pseudo first order kinetic reaction (g)Quasisecond-order kinetic reaction under optimal conditions (h)Quasi-second-order kinetic reaction under low PMS dosage 

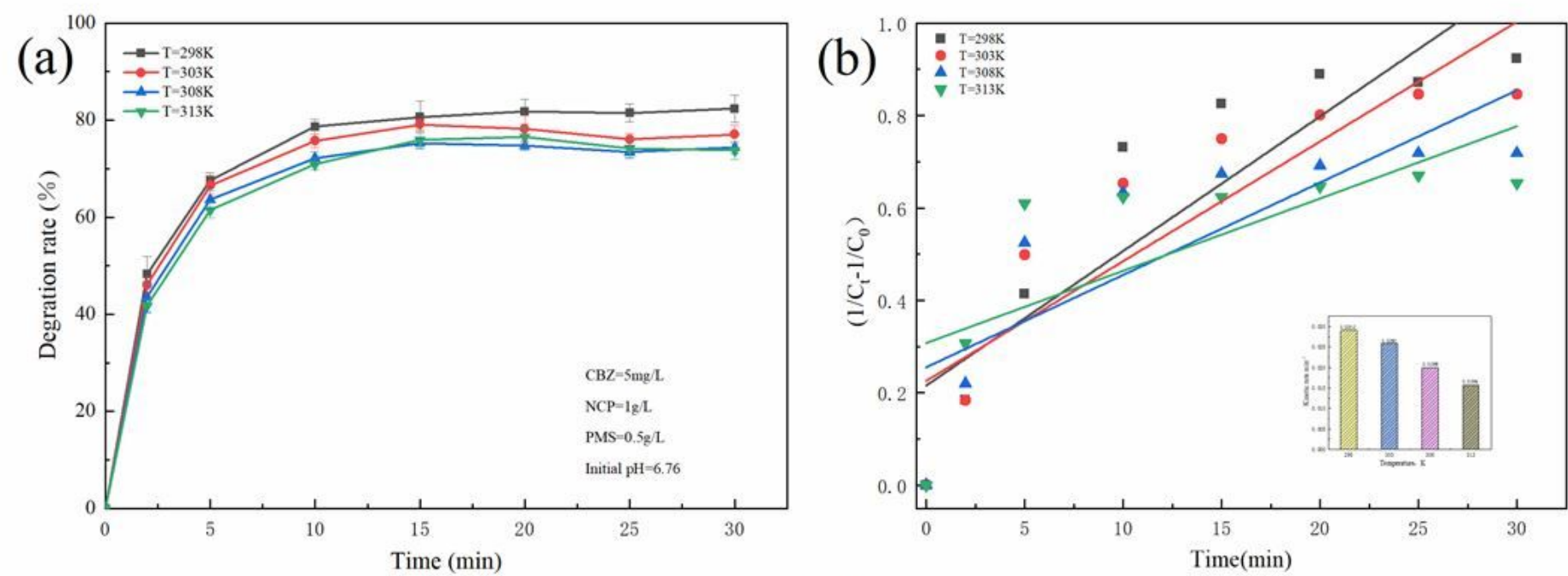

(c)

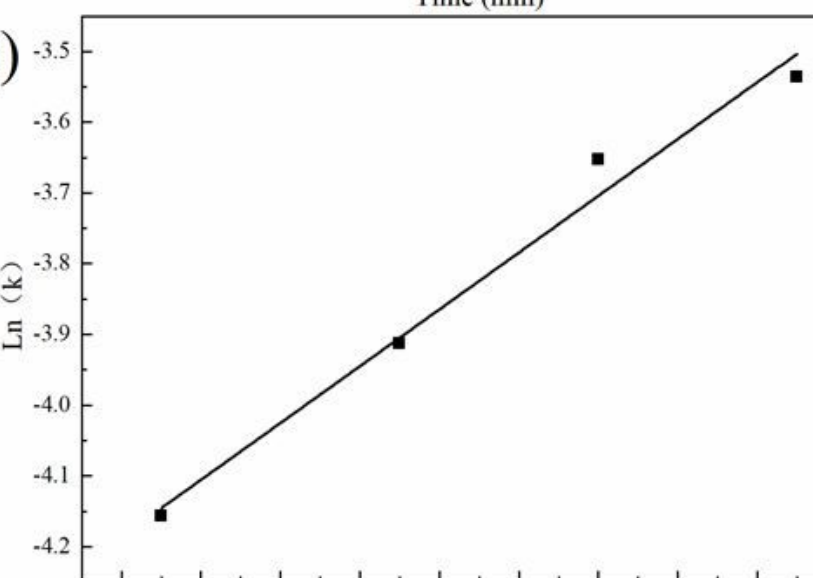

(d)

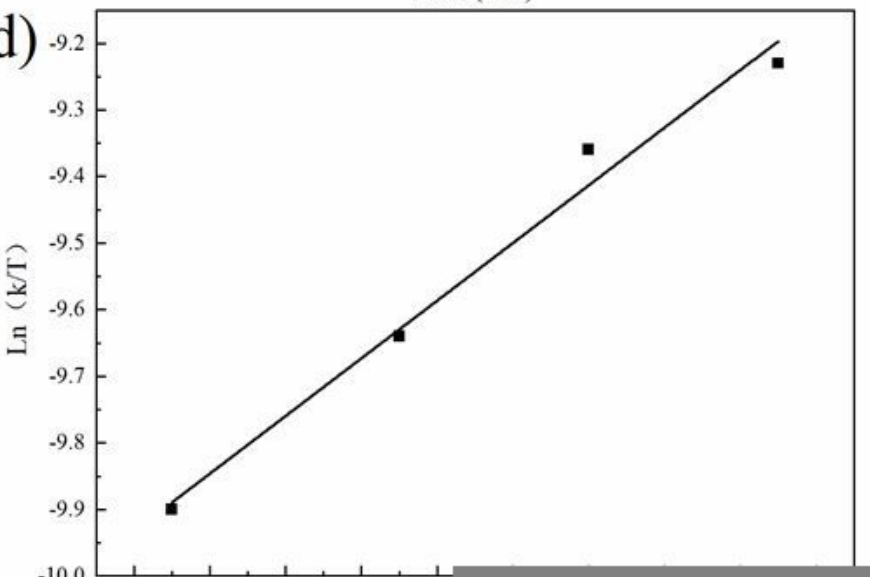

Figure 3

(a)Removal of CBZ by NCP/PMS system at different temperatures:(b)Pseudo-second-order kinetics at different temperatures (c)The influence of NCP dosage on the reaction system c)Arrhenius image of NCP/PMS removal process of CBZ (d)Eyring image of NCP/PMS removal process of CBZ 

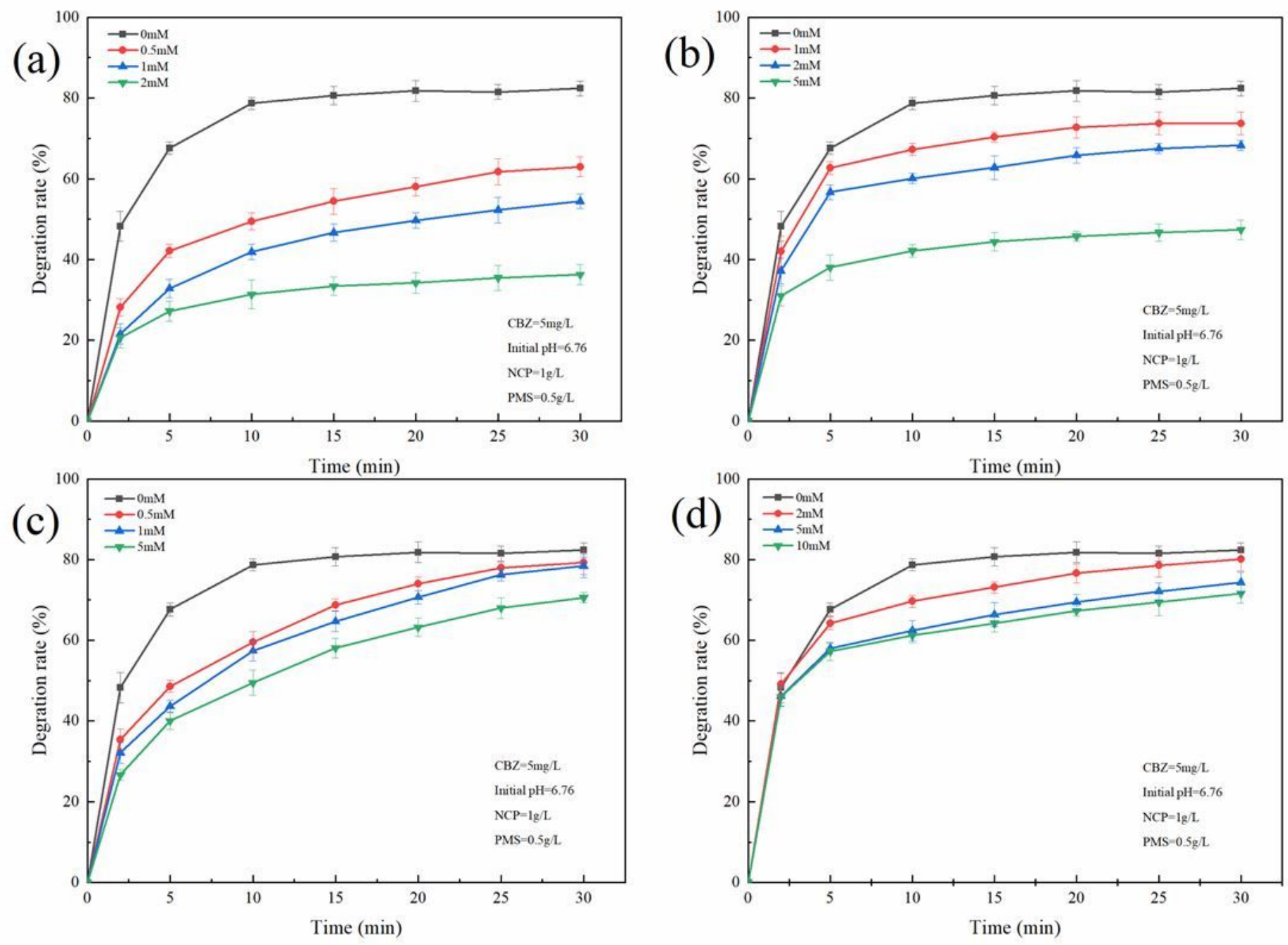

Figure 4

囚a冈The influence of $\mathrm{HCO}_{3}{ }^{-}$on the reaction system®b) The influence of $\mathrm{Cl}^{-}$on the reaction system (c)The influence of $\mathrm{H}_{2} \mathrm{PO}_{4}$-on the reaction system (d)The influence of $\mathrm{SO}_{4}{ }^{2-}$ on the reaction system 


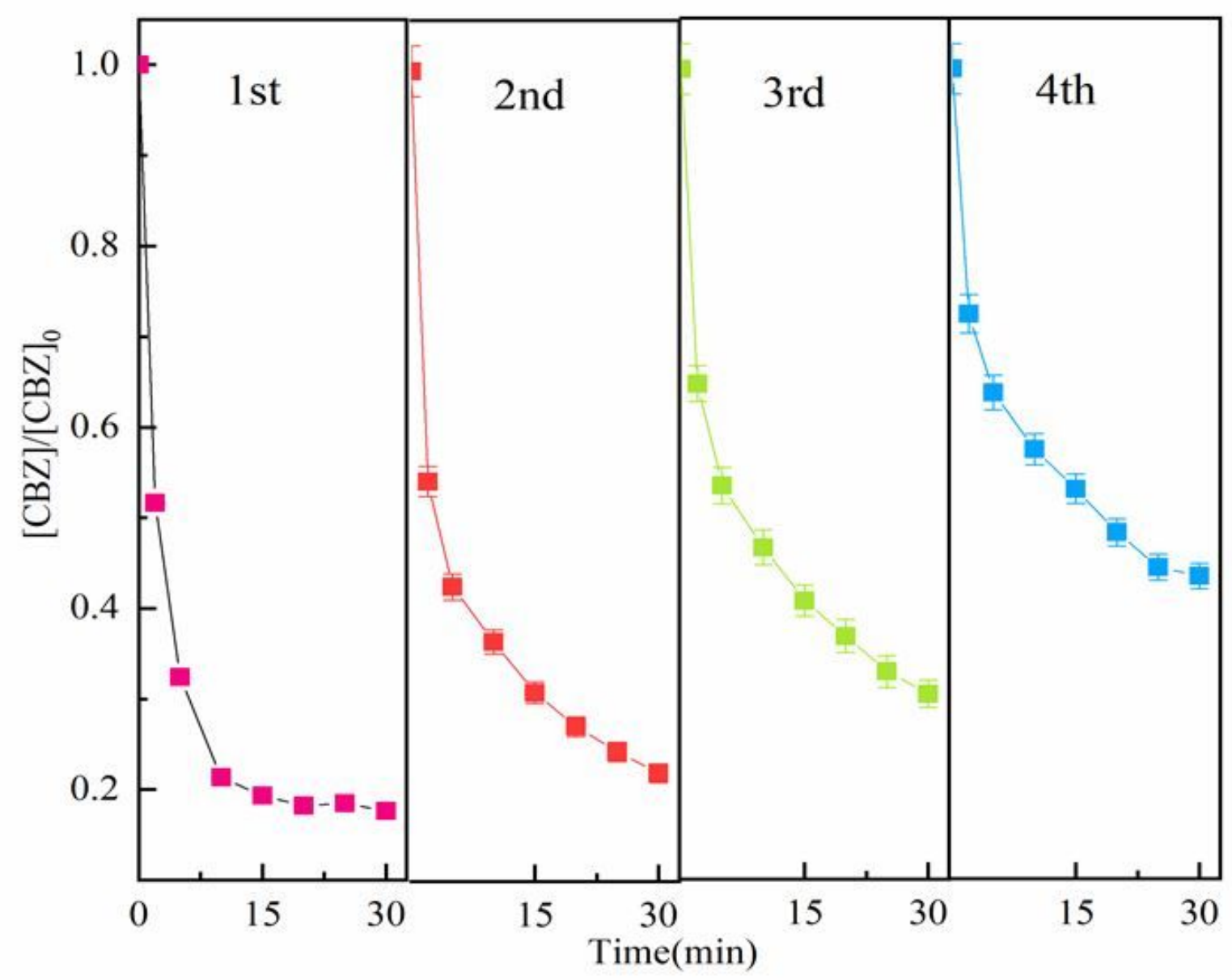

Figure 5

The influence of inorganic anions on the reaction system (in order of inhibition)

(a)

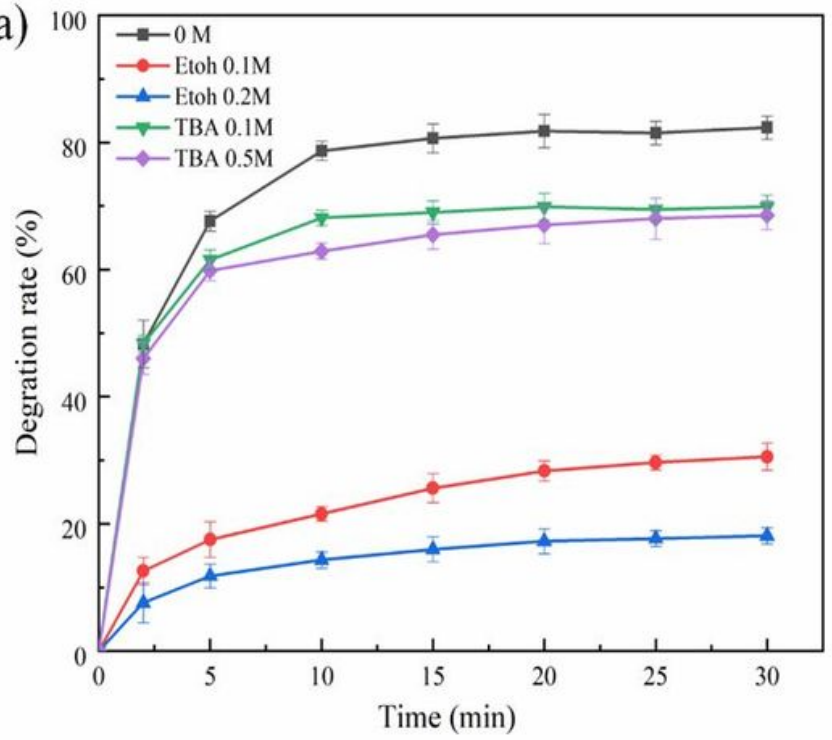

(b)

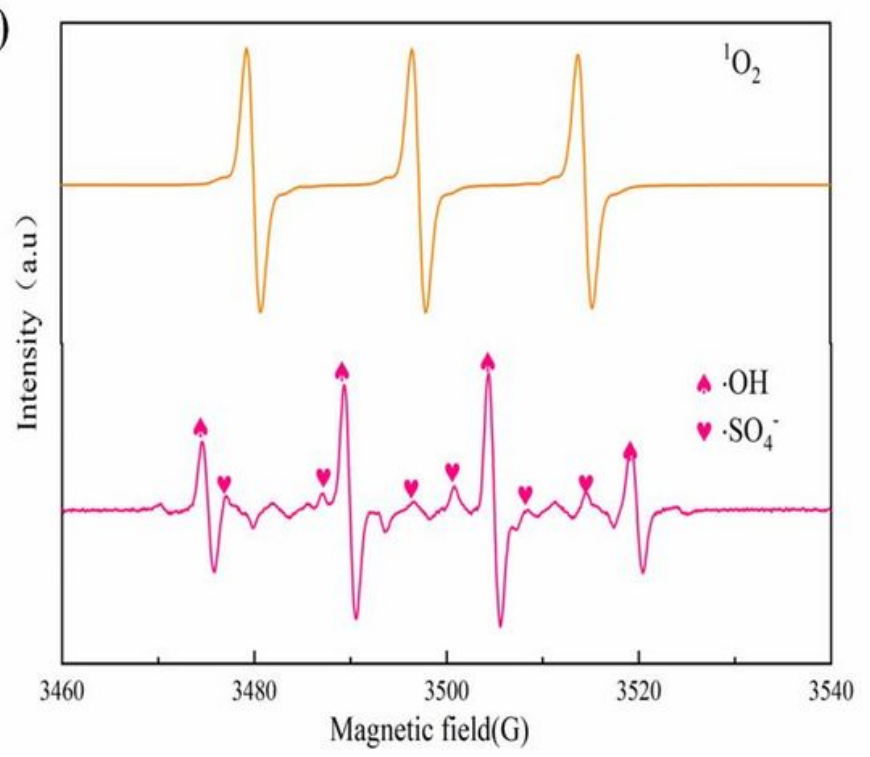

Figure 6

(a囚Free radical quenching experiment囚b)The EPR spectral obtained from NCP/PMS system 


\section{Figure 7}

(a囚ICP-MS analysis of metallic iron and copper冈b)The EPR spectral obtained from NCP/PMS system

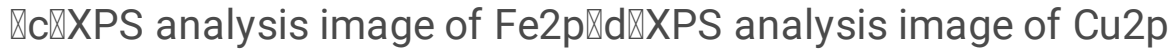

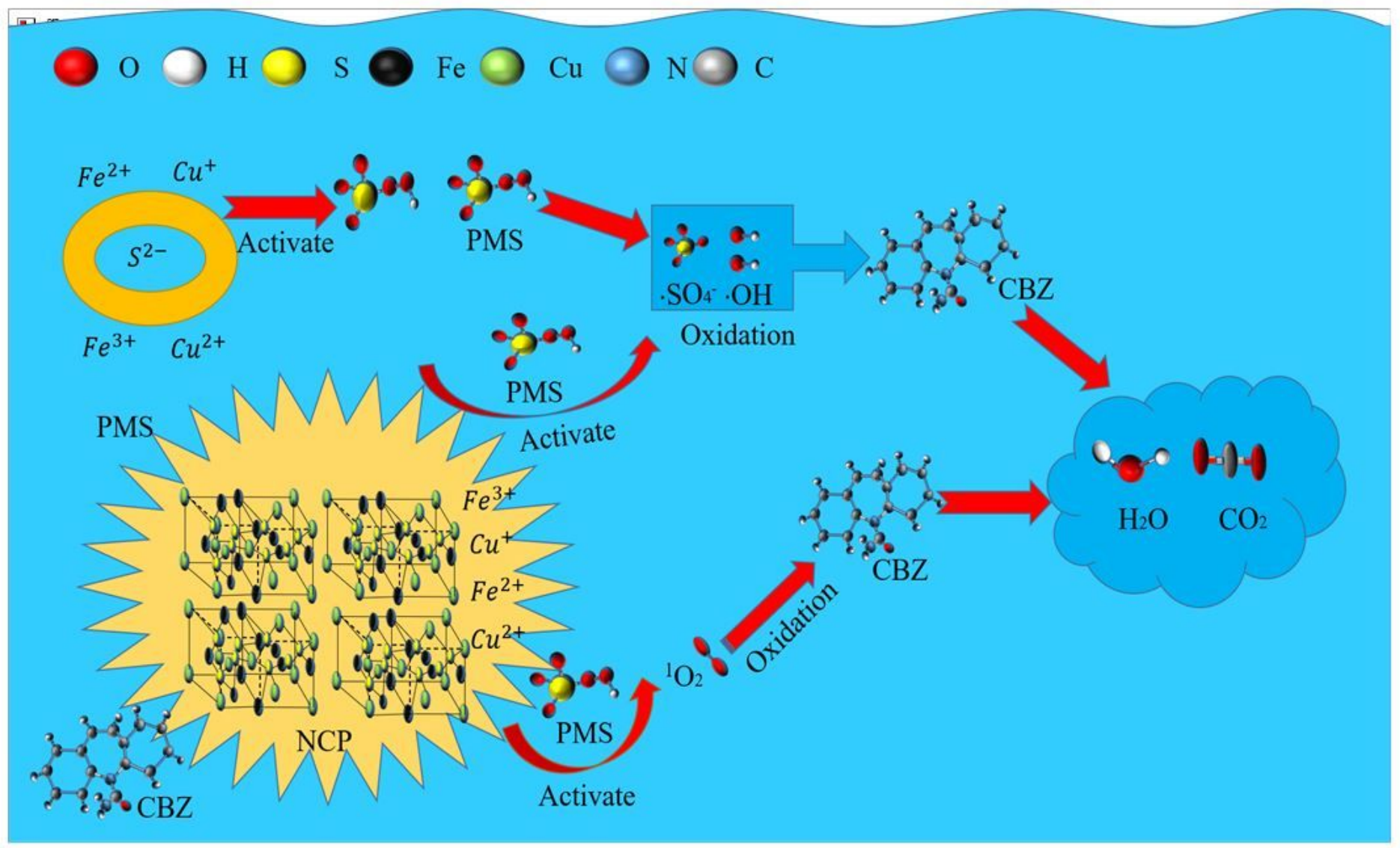

\section{Figure 8}

The possible degradation mechanism of CBZ in NCP/PMS system. 